Lílian Corrêa Costa Beber $^{1}$

Bióloga, mestranda em Atenção Integral a Saúde pela universidade Regional do Noroeste do estado do Rio Grande do Sul (UNIJUí). ljuí, RS. Brasil. E-mail:

liliantutty@hotmail.com

\section{Daiana Meggiolaro}

\section{Gewehr ${ }^{1}$}

Farmacêutica, mestranda em Atenção Integral a Saúde pela Universidade Regional do Noroeste do estado do Rio Grande do Sul (UNIJUÍ). ljuí, RS. Brasil. E-mail: daiagewehr@hotmail.com.

\section{Luana Cecconello ${ }^{1}$}

Fisioterapeuta, mestranda em Atenção Integral a Saúde pela Universidade Regional do Noroeste do estado do Rio Grande do Sul. (UNIJUÍ). Ijuí, RS. Brasil. E-mail: luanacecconello@hotmail.com

\section{Maicon Machado}

\section{Sulzbacher ${ }^{1}$}

Enfermeiro, mestrando em Atenção Integral a Saúde pela Universidade Regional do Noroeste do estado do Rio Grande do Sul (UNIJUí). ljuí, RS. Brasil. E-mail: maiconsulzbacher@hotmail.com

Thiago Gomes Heck ${ }^{1}$ Educador Físico, Doutor em Ciências do Movimento Humano, docente do

Departamento de Ciências da Vida da Universidade Regional do Noroeste do estado do Rio Grande do Sul (UNIJUÍ). ljuí, RS. Brasil. E-mail:

thiago.heck@unijui.edu.br

Evelise Moraes Berlezi ${ }^{1}$

Fisioterapeuta, Doutora em Gerontologia Biomédica, docente do Departamento de Ciências da Vida da

Universidade Regional do Noroeste do estado do Rio Grande do Sul (UNIJUÍ). ljuí, RS. Brasil. E-mail: evelise@unijui.edu.br

\section{FATORES DE RISCO PARA DOENÇAS RESPIRATÓRIAS EM CRIANÇAS BRASILEIRAS: revisão integrativa}

\author{
Risk factors for respiratory disease in Brazilian children: \\ integrative review
}

\section{RESUMO}

As doenças respiratórias estão entre as principais causas de internação hospitalar de crianças, que são mais suscetíveis ao desenvolvimento de doenças respiratórias graves. Diversos fatores podem influenciar na sua incidência, comportamentais, ambientais, como a exposição à poluição atmosférica e as variações climáticas. O objetivo desse trabalho foi elencar fatores de risco que contribuem para a incidência de doenças respiratórias em crianças brasileiras. Foi realizada revisão integrativa da literatura, com a pergunta norteadora: "Quais os principais fatores de risco para doenças respiratórias em crianças brasileiras?". Foram incluídos na revisão 20 artigos. Quanto aos fatores associados as doenças respiratórias, $50 \%$ (10) referiram a poluição e queimadas, 20\% (04) a condições climáticas naturais, 15\% (03) a infecções virais, $10 \%$ (02) a fatores comportamentais e/ou domésticos e 10\% (02) mencionaram a história da doença na família. Dos estudos que investigaram a poluição atmosférica, $88,8 \%$, evidenciaram que há um aumento na incidência de eventos respiratórios mesmo em níveis que não são considerados danosos pela Organização Mundial da Saúde. A poluição atmosférica foi o principal fator de risco investigado pelos estudos e o MP2,5 foi o principal poluente mencionado.

PALAVRAS-CHAVE: Saúde da Criança. Doenças Respiratórias. Poluentes Atmosféricos. Mudança Climática.

\section{ABSTRACT}

Respiratory disease are among the major causes of children hospitalization, who are the most susceptible to development of severe respiratory diseases. Various factors can influence on their incidence, behavior, ambient, as exposure to atmospheric pollution and climatic variations. The aim of this work was to evaluate the literature about the risk factors to incidence of respiratory diseases in Brazilian children. Literature integrative review was did, with the guiding question: "What are the main risk factors for respiratory diseases in Brazilian children?" Results: Were included in the review 20 articles. About the factors associated with respiratory disease, $50 \%$ (10) referred to the pollution and burned, $20 \%$ (04) to natural climatic conditions, $15 \%(03)$ to viral infections, $10 \%$ 
(02) to behavior factors and/or domestics and 10\% (02) mentioned family history of the disease. Among the studies that investigated atmospheric pollution, $88.8 \%$ evidenced that there is an increase of respiratory events incidence even in levels not considered harmful by the World Health Organization. The atmospheric pollution was the principle risk factor investigated by these studies and the PM 2.5 was the principle pollutant mentioned.

KEYWORDS: Child Health. Respiratory Diseases. Air Pollutants. Climate Change.

\section{INTRODUÇÃO}

As doenças respiratórias são importantes fatores de internação e morbimortalidade no mundo (SOUZA et al., 2012) e estão entre as principais causas de internação hospitalar de crianças (ANDRADE-FILHO et al., 2013), que são mais suscetíveis ao desenvolvimento de doenças respiratórias graves (ARRUDA et al., 2014). Desde 1995 a Organização Mundial de Saúde (OMS) declara que grande parte das crianças brasileiras apresenta cerca de quatro a seis infecções respiratórias agudas por ano, impactando diretamente na saúde pública (WHO, 2013).

O Brasil é um dos países com maiores taxas de prevalência de asma e rinite alérgica do mundo (GUILHERME, 2012). Doenças por causas virais e bacterianas também são importantes na morbimortalidade infantil. Em revisão sistemática verificou-se que a pneumonia foi a principal causa de internações por condições sensíveis à atenção primária em crianças menores de 5 anos (PEDRAZA; SALLES, 2014).

Diversos fatores podem influenciar na incidência dessas doenças, com destaque àqueles associados ao comportamento, como o tabagismo, e ao ambiente, como a exposição à poluição atmosférica e as variações climáticas. Os poluentes atmosféricos podem ser divididos em gases, como ozônio (O3), óxidos de nitrogênio (NOx), e particulados, sendo os últimos mais elucidados em estudos experimentais e epidemiológicos (EPA, 2011). Sob a denominação de Material Particulado (MP) se encontra um conjunto de poluentes formados a partir dos processos de combustão e constituídos de poeira, fumaça e todo o tipo de material sólido e líquido que se mantém suspenso na atmosfera. O MP é classificado conforme o tamanho de suas partículas, em partículas grossas MP10 $(2,5$ a $10 \mu \mathrm{m})$, partículas finas - MP2,5 $(<2,5 \mu \mathrm{m})$ ou ultrafinas - MP0,1 $(<0,1 \mu \mathrm{m})$ (AMBIENTE, 2018).

O conhecimento da etiologia das doenças respiratórias proporciona maior resolubilidade na atenção primária à saúde e norteia as ações de promoção e prevenção. Deste modo, pode-se reduzir as internações hospitalares e no contexto de implicações ao Sistema Único de Saúde (SUS) diminuir os custos públicos, a incidência e a mortalidade infantil por doenças respiratórias. Nessa perspectiva, as revisões integrativas são uma importante fonte de informações ao analisar o que se tem disponível na literatura científica e assim dar subsídios para a tomada de decisões, principalmente na área saúde (WHITTEMORE; KNAFL, 2005).

Diante do exposto o presente estudo objetiva avaliar a literatura quanto a fatores que contribuem para a incidência das doenças respiratórias em crianças brasileiras. 


\section{COLETA DE DADOS}

Trata-se de um estudo de revisão integrativa da literatura, realizada com base nas recomendações do Preferred Reporting Items for Systematic Reviews and Meta-Analyses (PRISMA) (GALVÃO; PANSANI; HARRAD, 2015), com a seguinte pergunta norteadora: "Quais os principais fatores de risco para doenças respiratórias em crianças brasileiras?". A busca dos artigos foi realizada em maio de 2017, nos portais online Periódicos da Capes, Biblioteca Virtual de Saúde (BVS), PubMed e Scientific Electronic Library Online (SciELO). Foram utilizados os Descritores em Ciências da Saúde (DeCs) doenças respiratórias, crianças e Brasil e seus equivalentes em inglês.

Para a seleção dos artigos utilizou-se os seguintes critérios: estudos realizados no Brasil, publicados no período de 2012 a 2017 e que abordassem as possíveis causas de doença respiratória em crianças. Foram excluídos estudos de revisão, artigos não encontrados na íntegra e estudos com nível de evidência inferior a quatro (CAVALCANTI et al., 2011).

Após a obtenção da lista dos estudos das bases de dados realizou-se a seleção dos mesmos por dois pesquisadores, de forma independente e sistemática. Ambos os pesquisadores fizeram a identificação inicial a partir dos títulos das publicações e posteriormente pelos resumos. Após a seleção prévia das publicações, uma nova avaliação foi feita pelos dois pesquisadores que determinaram de forma consensual os estudos a serem lidos na íntegra e incluídos na revisão. No total foram localizados 319 artigos, dos quais 20 foram incluídos, conforme descrito na Figura 1.

Figura 1: Fluxograma da seleção dos estudos, de acordo com os critérios de inclusão e exclusão préestabelecidos (2017)

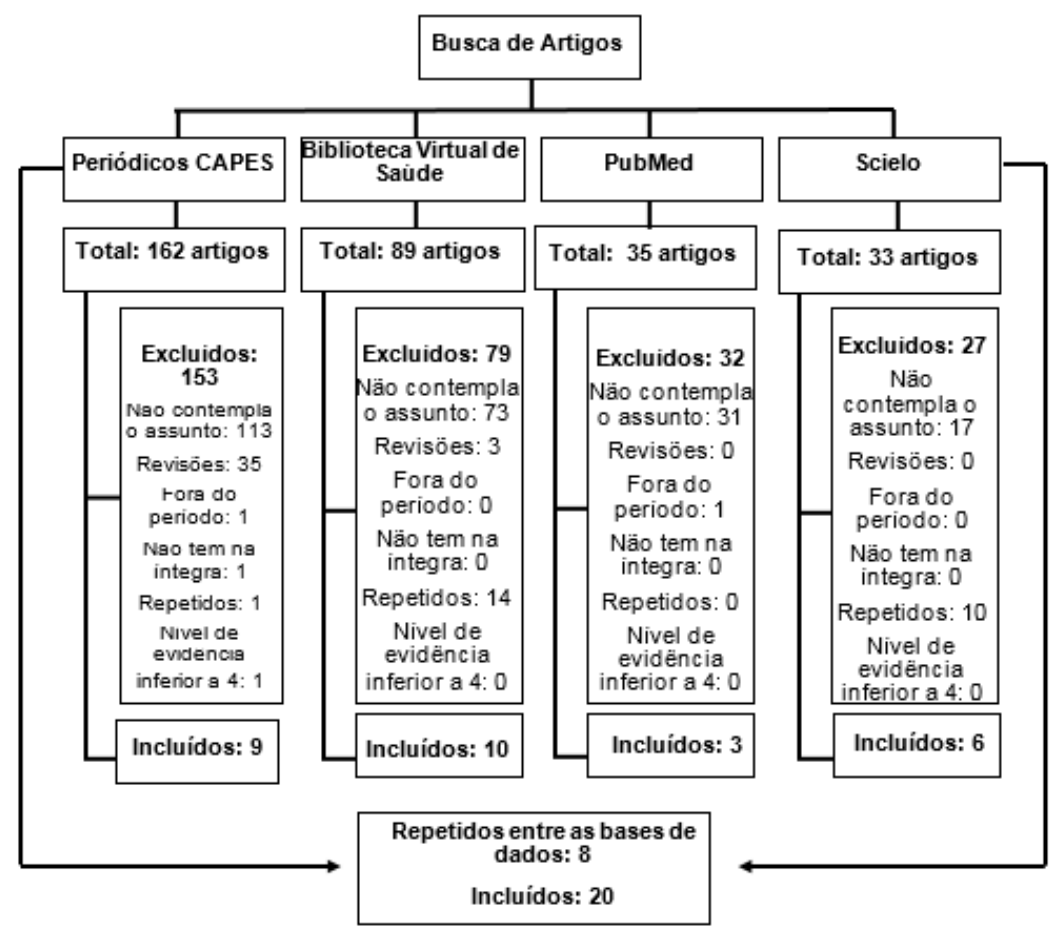




\section{RESULTADOS}

Em relação ao delineamento dos 20 artigos selecionados, $60 \%$ (12) eram estudos ecológicos, 20\% (04) transversais, 10\% (02) de coorte e 10\% (02) ensaios clínicos ou de série de casos. No que se refere ao local de realização, $50 \%$ (10) dos estudos foram realizados no Sudeste do Brasil, 20\% (04) no Sul, $15 \%(03)$ no Norte, $10 \%$ (02) no Centro-Oeste e 5\% (01) no Nordeste.

Quanto aos fatores associados ao desenvolvimento de doenças respiratórias, $50 \%$ (10) deles referiram-se a condições climáticas decorrentes de atividades antrópicas, tais como, poluição e queimadas, 20\% (04) a condições climáticas naturais, como a sazonalidade, temperatura, umidade e taxa de precipitação, $15 \%$ (03) a infecções virais, 10\% (02) referiram-se a fatores comportamentais e/ou domésticos, como o uso de cobertor de lã, tabagismo dos pais, e 10\% (02) mencionaram a história da doença na família como fator de risco/causa para doenças respiratórias. Houve artigos que mencionaram mais de um fator de risco, por isso a discrepância nos números na soma final. Os resultados estão apresentados na Tabela 1. 


\section{Revista Interdisciplinar de Estudos em Saúde da UNIARP \\ ISSN: 2238-832X}

Tabela 1: Artigos selecionados apartir da busca pelos descritores: “doenças respiratórias, crianças e Brasil", após aplicação dos critérios de inclusão e exclusão.

\begin{tabular}{|c|c|c|c|c|c|c|}
\hline Artigo & Tipo de estudo & $\begin{array}{c}\text { Amostra e } \\
\text { Faixa etária }\end{array}$ & $\begin{array}{c}\text { Local do } \\
\text { estudo }\end{array}$ & Fatores investigados & Doença & NE \\
\hline $\begin{array}{l}\text { Andrade Filho } \\
\text { et al., } 2013\end{array}$ & $\begin{array}{l}\text { Descritivo ecológico } \\
\text { de séries temporais }\end{array}$ & $\begin{array}{l}\mathrm{n}=61.707 \\
29 \text { dias à } 9 \\
\text { anos }\end{array}$ & $\begin{array}{l}\text { Manaus } \\
\text { (AM) }\end{array}$ & $\begin{array}{c}\text { Umidade, } \\
\text { Precipitação ( } 86 \% \text { das } \\
\text { internaçôes) }\end{array}$ & $\begin{array}{l}\text { Pneumonia, } \\
\text { gripe, asma }\end{array}$ & 5 \\
\hline $\begin{array}{l}\text { Brandão et al., } \\
2017\end{array}$ & $\begin{array}{l}\text { Prospectivo de } \\
\text { coorte }\end{array}$ & $\begin{array}{l}\mathrm{n}=672 \\
\text { Até } 6 \text { anos }\end{array}$ & $\begin{array}{l}\text { Feira de } \\
\text { Santana } \\
\text { (BA) }\end{array}$ & $\begin{array}{l}\text { Idade paterna, história } \\
\text { familiar de asma ou } \\
\text { bronquiolite viral } \\
\text { aguda. }\end{array}$ & Asma & 6 \\
\hline $\begin{array}{l}\text { César et al., } \\
2013\end{array}$ & $\begin{array}{c}\text { Ecológico de séries } \\
\text { temporais }\end{array}$ & $\begin{array}{c}\mathrm{n}=437 \\
\text { Até } 10 \text { anos }\end{array}$ & $\begin{array}{l}\text { Piracicaba } \\
\quad \text { (SP) }\end{array}$ & $\mathrm{MP}_{2,5}$ & Pneumonia e asma & 5 \\
\hline $\begin{array}{c}\text { César et al., } \\
2016\end{array}$ & $\begin{array}{c}\text { Ecológico de séries } \\
\text { temporais }\end{array}$ & $\begin{array}{l}\mathrm{n}=140 \\
\text { Até } 10 \text { anos }\end{array}$ & $\begin{array}{l}\text { Taubaté } \\
\text { (SP) }\end{array}$ & $\begin{array}{c}\mathrm{MP}_{2,5} \text {, temperatura } \\
\text { aparente } \mathrm{e} \\
\text { sazonalidade }\end{array}$ & Pneumonia e asma & 5 \\
\hline $\begin{array}{l}\text { Gonçalves et } \\
\text { al., } 2016\end{array}$ & $\begin{array}{c}\text { Observacional e } \\
\text { transversal }\end{array}$ & $\begin{array}{c}n=54 \\
7 \text { a } 12 \text { anos }\end{array}$ & $\begin{array}{l}\text { Campinas } \\
\text { (SP) }\end{array}$ & $\begin{array}{c}\text { Uso de cobertor de lã } \\
\text { Muito baixo peso ao } \\
\text { nascer }\end{array}$ & Asma & 5 \\
\hline $\begin{array}{l}\text { Guilherme et } \\
\text { al., } 2012\end{array}$ & $\begin{array}{l}\text { Observacional } \\
\text { transversal } \\
\text { prospectivo }\end{array}$ & $\begin{array}{c}n=396 \\
6 \text { a } 20 \text { anos }\end{array}$ & $\begin{array}{l}\text { Maringá } \\
(\mathrm{PR})\end{array}$ & $\begin{array}{c}\text { Poeira doméstica, } \\
\text { ácaros }\end{array}$ & Alergias respiratórias & 5 \\
\hline $\begin{array}{l}\text { Leotte et al., } \\
2017\end{array}$ & Transversal & $\mathrm{n}=755$ & Curitiba (PR) & Baixas temperaturas & Infecções virais & 5 \\
\hline $\begin{array}{c}\text { Roman, et al., } \\
2015\end{array}$ & $\begin{array}{l}\text { Ecológico de série } \\
\text { temporal }\end{array}$ & $\mathrm{n}=352$ & $\begin{array}{c}\text { Taubaté } \\
\text { (SP) }\end{array}$ & Óxidos de nitrogênio & Doenças respiratórias & 5 \\
\hline $\begin{array}{c}\text { Souza et al., } \\
2012\end{array}$ & Ecológico & $\begin{array}{c}\mathrm{n}=6.630 \\
\text { crianças, } \\
2.866 \\
\text { lactentes } \\
\text { Lactentes (1 } \\
\text { a } 4 \text { anos) } \\
\text { Crianças } \\
\text { (5 a } 14 \text { anos) }\end{array}$ & $\begin{array}{c}\text { Campo } \\
\text { Grande (MS) }\end{array}$ & $\begin{array}{l}\text { Temperatura, umidade } \\
\text { relativa, precipitação, } \\
\text { velocidade dos ventos } \\
\text { e índices de conforto } \\
\text { térmico. }\end{array}$ & Pneumonia & 5 \\
\hline
\end{tabular}




\begin{tabular}{|c|c|c|c|c|c|c|}
\hline $\begin{array}{l}\text { Arruda et al., } \\
2014\end{array}$ & $\begin{array}{l}\text { Prospectivo de } \\
\text { coorte }\end{array}$ & $n=246$ & $\begin{array}{c}\text { Curitiba (PR) } \\
\text { Porto Alegre } \\
\text { (RS) } \\
\text { Ribeirão } \\
\text { Preto (SP) }\end{array}$ & $\begin{array}{l}\text { Causa viral: Vírus } \\
\text { Sincicial Respiratório }\end{array}$ & $\begin{array}{l}\text { Infecções do trato } \\
\text { respiratório }\end{array}$ & 6 \\
\hline $\begin{array}{l}\text { Albuquerque et } \\
\text { al., } 2012\end{array}$ & $\begin{array}{l}\text { Casos clínicos e } \\
\text { série de dados }\end{array}$ & $\begin{array}{c}n=205 \\
3,3 \text { anos }\end{array}$ & $\begin{array}{l}\text { Teresópolis } \\
\text { (RJ) }\end{array}$ & Causa viral & $\begin{array}{l}\text { Infecção do trato } \\
\text { respiratório }\end{array}$ & 4 \\
\hline $\begin{array}{l}\text { Rodrigues et } \\
\text { al., } 2013\end{array}$ & $\begin{array}{c}\text { Ecológico da } \\
\text { distribuição } \\
\text { temporal e espacial }\end{array}$ & $\begin{array}{c}\mathrm{n}=35,4 / 1000 \\
<5 \text { anos }\end{array}$ & $\begin{array}{l}\text { Rondônia } \\
\text { (RO) }\end{array}$ & Queimadas & Doenças respiratórias & 5 \\
\hline $\begin{array}{l}\text { Silva et al., } \\
2013^{\mathrm{a}}\end{array}$ & $\begin{array}{l}\text { Ecológico de série } \\
\text { temporal }\end{array}$ & $\begin{array}{l}\mathrm{n}=1.152 \\
<5 \text { anos }\end{array}$ & Cuiabá (MT) & $\begin{array}{c}\mathrm{MP}_{2,5} \text { gerado por } \\
\text { queimadas }\end{array}$ & Doenças respiratórias & 5 \\
\hline $\begin{array}{l}\text { Vieira et al., } \\
2012\end{array}$ & Ecológico & $\begin{array}{c}n=64 \\
6 \text { e } 10 \text { anos }\end{array}$ & $\begin{array}{l}\text { São Paulo } \\
\text { (SP) }\end{array}$ & $\begin{array}{l}\text { Oxidos de nitrogênio e } \\
\text { Ozônio }\end{array}$ & Asma e sibilância & 5 \\
\hline $\begin{array}{l}\text { Silva et al., } \\
2013^{\circ}\end{array}$ & $\begin{array}{l}\text { Casos clínicos e } \\
\text { série de dados }\end{array}$ & $\begin{array}{l}n=260 \\
<3 \text { anos }\end{array}$ & $\begin{array}{l}\text { Porto Alegre } \\
\text { (RS) }\end{array}$ & Causa viral & $\begin{array}{l}\text { Infecção do trato } \\
\text { respiratório inferior }\end{array}$ & 4 \\
\hline $\begin{array}{l}\text { Freitas et al., } \\
\qquad 2012\end{array}$ & Transversal & $\begin{array}{c}n=400 \\
5 \text { a } 8 \text { anos }\end{array}$ & $\begin{array}{c}\text { Outeiro e } \\
\text { Combú (PA) }\end{array}$ & $\begin{array}{l}\text { História familiar de } \\
\text { eczema ou rinite, } \\
\text { histórico pessoal de } \\
\text { eczema, tosse noturna } \\
\text { nos dois últimos anos, } \\
\text { alérgenos aéreos } \\
\text { provenientes de gatos } \\
\text { domésticos }\end{array}$ & Asma & 5 \\
\hline $\begin{array}{c}\text { Nardocci et al. } \\
2013\end{array}$ & $\begin{array}{c}\text { Ecológico de série } \\
\text { temporal }\end{array}$ & $\begin{array}{l}<5 \text { anos e } \\
>39 \text { anos }\end{array}$ & $\begin{array}{l}\text { Cubatão } \\
\text { (SP) }\end{array}$ & $\begin{array}{c}\mathrm{MP}_{10} \\
\mathrm{Ozônio} \\
\mathrm{SO}_{2} \\
\end{array}$ & $\begin{array}{c}\text { Doenças respiratórias e } \\
\text { cardiovasculares }\end{array}$ & 5 \\
\hline
\end{tabular}


Dos nove (09) artigos que avaliaram o impacto da poluição sobre as internações por doenças respiratórias de crianças, 44,44\% (04) mencionaram o material particulado fino (MP2,5), 33,33\% (03) óxidos de nitrogênio, 22,2\% (02) o material particulado grosso (MP10), 11,11\% (01) o ozônio (O3) e o dióxido de enxofre (SO2), além disso, há o relato de mais de um poluente químico por estudo, por isso a discrepância nos números. Os resultados estão apresentados na Tabela 2.

Tabela 2: - Distribuiçäo dos estudos incluídos na revisåo sistemática que avaliaram os efeitos da exposiçăo a poluiçäo na incidência doenças respiratórias de crianças.

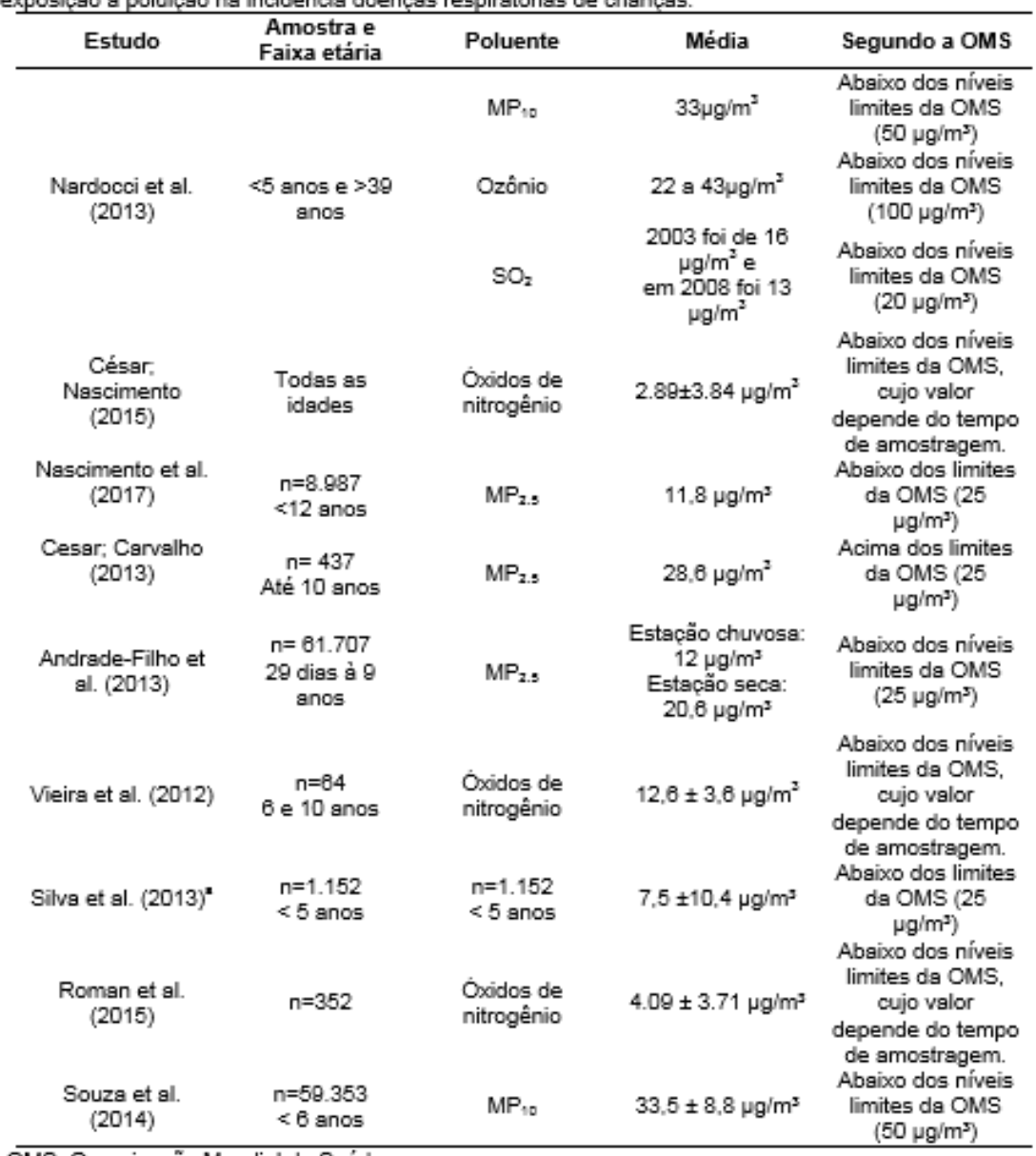

Devido a relevância dos poluentes atmosféricos nas internações hospitalares por doenças respiratórias, buscou-se verificar quais as concentrações atmosféricas dos poluentes nos estudos. Todos foram realizados em cidades reconhecidamente poluídas, mas $88,88 \%$ (08) dos trabalhos que estudaram a exposição a poluição atmosférica, encontraram aumento nas internações hospitalares pela exposição a médias diárias inferiores aos limites considerados danosos pela Organização Mundial da Saúde (OMS) (TABOSA et al., 2012). 
Em relação a faixa etária analisadas nos estudos, constatou-se que a maioria utilizou uma faixa etária ampla, sem estratificações nas análises. Destes estudos, $11,11 \%(01)$ analisou todas as idades, 22,22\% (02) até cinco anos e $55,55 \%$ (05) analisaram idades superiores. Apenas um não descreveu a faixa etária utilizada.

\section{DISCUSSÃO}

A incidência de doenças respiratórias em crianças é influenciada por diversos fatores, verificou-se através dessa revisão que, a poluição atmosférica foi o principal fator de risco relacionado a estas doenças, seguida de condições climáticas naturais e, em menor grau, infecções virais, fatores comportamentais e/ou domésticos e história da doença na família. Do mesmo modo, verificou-se que o poluente mais investigado, dentre os estudos filtrados é o MP2,5, e demonstrou-se que este, é danoso mesmo dentro dos limites ideais estabelecidos pela OMS (Tabela 2).

Os resultados apontam para a relevância da exposição a poluição atmosférica no desenvolvimento de doenças respiratórias (VIEIRA et al., 2012, ANDRADEFILHO et al., 2013, CESAR; CARVALHO, 2013, NARDOCCI et al., 2013, SILVA et al., 2013a, SOUZA et al., 2014, CÉSAR; NASCIMENTO et al, 2017, ROMAN et al., 2015; CESAR, 2016). Há importantes evidências de que a exposição a poluentes, principalmente o MP2,5, corresponde a um forte fator de risco para doenças respiratórias. Acima de $50 \mu \mathrm{g} / \mathrm{m} 3$, para cada suba de $10 \mu \mathrm{g} / \mathrm{m} 3$ nos níveis de MP2,5 houve aumento de $2 \%$ nas visitas clínicas, enquanto abaixo dessa concentração, a cada aumento nas mesmas proporções resultaram em acréscimo de $1 \%$ na mesma variável (SHEN et al., 2017). Nas cidades brasileiras, o aumento de 3 a $5 \mu \mathrm{g} / \mathrm{m} 3$ esteve associado ao aumento no risco de desenvolvimento de doenças respiratórias e nas internações hospitalares infantis que variou de acordo com a cidade (ROMAN et al., 2015, CESAR, 2016, NASCIMENTO et al., 2017).

Os impactos da poluição atmosférica sobre a saúde respiratória, cardiovascular e metabólica, vêm sendo estudados e destacados, uma vez que se trata de um fator de risco causado por atividades antrópicas, e passível de redução. Contudo, salienta-se que mesmo nos níveis considerados seguros pela OMS, a poluição atmosférica pode ter contribuído para o aumento no número de internações hospitalares de crianças por problemas respiratórios (Tabela 2).

Crianças até dois anos são mais suscetíveis aos efeitos da poluição atmosférica e, portanto, podem desenvolver sintomas respiratórios agudos mais facilmente (NASCIMENTO et al., 2017), pois apresentam maior ventilação pulmonar que adultos (VIEIRA et al., 2012, NASCIMENTO et al., 2017). Ainda, nessa faixa etária as crianças passam menos tempo em ambientes externos e, por essa razão, têm menor contato com poluição atmosférica. Contudo, o breve contato com a poluição pode ter efeitos mais severos (NARDOCCl et al., 2013, NASCIMENTO et al., 2017).

A inalação do MP2,5, devido ao tamanho aerodinâmico reduzido de suas partículas, pode danificar tecidos cardiopulmonares, ultrapassar a barreira alvéolo-capilar e atingir a circulação sanguínea, de modo que pode comprometer outros sistemas além do respiratório (RAJAGOPALAN; BROOK, 2012). A nível pulmonar, pode levar diretamente a formação de espécies reativas de oxigênio (ERO), ativar macrófagos e elevar a produção citocinas inflamatórias, 
propagando a resposta inflamatória (GHIO et al., 2002; ORONA et al., 2016; GURGUEIRA et al., 2002).

O MP10 é menos danoso que o MP2,5, devido ao maior tamanho aerodinâmico de suas partículas $(2,5-10 \mu \mathrm{m})$ que restringem o seu alcance ao trato respiratório superior (AMBIENTE, 2018). Na Região da Grande Vitória (Espírito Santo), o aumento de 10,49 $\mathrm{\mu g} / \mathrm{m} 3$ (intervalo interquartílico) nos níveis de MP10 levaram ao aumento de $3 \%$ do risco relativo estimado para atendimento hospitalar (SOUZA et al., 2014). Esse poluente tem como uma das principais fontes as queimadas, comuns na região Norte, na estação seca (ANDRADE-FILHO et al., 2013; RODRIGUES; HACON, 2013), onde a liberação de MP10 se sobrepõe a de MP2,5 (ANDRADE-FILHO et al., 2013).

Os níveis de $\mathrm{NO} 2$ e $\mathrm{O} 3$ também foram correlacionados ao risco de incidência de asma e pneumonia em crianças em São Paulo (VIEIRA et al., 2012). O aumento de $3 \mu \mathrm{g} / \mathrm{m} 3$, correspondente a diferença interquartílica, nas concentrações de NOx gerou aumentos percentuais na ordem de $14,8 \%$, mesmo que as concentrações não tenham ultrapassado os limites considerados aceitáveis (ROMAN et al., 2015). NOx representa todos os óxidos de nitrogênio presentes na atmosfera, mas como o NO é rapidamente oxidado a NO2, a concentração de NOx reflete a concentração de NO2 (CÉSAR; NASCIMENTO, 2015). O O3 também foi correlacionado com problemas respiratórios (NARDOCCI et al., 2013). O aumento da concentração de $\mathrm{O} 3 \mathrm{em} 10 \mu \mathrm{g} / \mathrm{m} 3$ esteve associada ao aumento de $3,91 \%$ de doenças respiratórias em crianças com menos de 5 anos (NARDOCCl et al., 2013).

Esses poluentes são capazes de aumentar a permeabilidade epitelial dos brônquios, consequentemente, a infiltração leucocitária e a liberação de mediadores inflamatórios (CÉSAR; NASCIMENTO, 2015). Considerando que a ventilação pulmonar de crianças é maior que adultos (VIEIRA et al., 2012), elas se tornam mais propensas a inflamação das vias aéreas superiores e inferiores pela exposição a poluição atmosférica e desse modo, representam um grupo de risco para tais efeitos. A exposição crônica a poluição atmosférica sensibiliza o trato respiratório precocemente, que já se encontra inflamado por outras questões de saúde. Logo, a poluição representa uma fonte de sensibilização alérgica precoce e contínua.

Os estudos que avaliaram os efeitos da poluição atmosférica sobre as internações hospitalares de crianças por problemas respiratórias foram desenvolvidos em cidades brasileiras reconhecidamente poluídas. Salienta-se que $88 \%$ destes trabalhos trouxeram médias diárias de exposição dentro dos limites aceitáveis para a OMS, portanto, esses dados também podem ser extrapolados para cidades pequenas, cuja qualidade do ar ainda se encontra adequada segundo os parâmetros da OMS.

Ao contrário da poluição atmosférica por fonte industrial e automobilística que é caracterizada pela cronicidade, a poluição decorrente de queimadas é sazonal (SILVA et al., 2013a), e também está relacionada ao aumento no número de internações por doenças respiratórias (RODRIGUES; HACON, 2013; SILVA et al., 2013a). Além disso, a exposição aos poluentes decorrentes das queimadas pode exceder os locais de ocorrência delas, em razão das massas de ar, levando a maior incidência de doenças respiratórias em outras localidades (RODRIGUES; HACON, 2013). A exposição a poluentes atmosféricos, independentemente da fonte, muitas vezes pode potencializar os efeitos dos fatores climáticos sobre as internações por eventos respiratórios, e vice-versa. $\mathrm{Na}$ região de Manaus, as internações hospitalares parecem estar mais relacionadas a variáveis meteorológicas, especialmente a umidade, do que aos 
poluentes oriundos da queima de biomassa (ANDRADE-FILHO et al., 2013). Há evidências de que existe relação direta entre as variações meteorológicas e a saúde da população, sobretudo no comprometimento da função pulmonar e na incidência de doenças respiratórias (ANDRADE-FILHO et al., 2013, CARVALHO; CARVALHO, 2016).

Variações de temperatura e umidade também estão relacionadas a alterações nas concentrações de poluentes e, consequentemente, as internações por doenças respiratórias. A elevação na temperatura esteve associada a elevação das concentrações de MP2,5 (CÉSAR, 2016). Do mesmo modo, tanto o aumento quanto a redução brusca da temperatura estão relacionadas ao desenvolvimento de doenças respiratórias, assim como a redução da umidade e do conforto térmico para a população (SOUZA et al., 2012).

$\mathrm{Na}$ região Sul, a maioria das queixas por problemas respiratórios ocorreu nos meses mais frios (julho-setembro) (GUILHERME, 2012, SILVA et al., 2013b; LEOTTE et al., 2017), e nos meses que prenunciam a chegada dessa estação (SOUZA et al., 2012), porém, não foram correlacionadas com as taxas de precipitação (LEOTTE et al., 2017). No Rio de Janeiro, a maioria das queixas por infecções respiratórias virais se deu entre o fim do outono e a primavera (ALBUQUERQUE et al., 2012).

Dos estudos incluídos, três verificaram a relação de infecções virais com problemas respiratórios de crianças. Os vírus são grandes responsáveis pela incidência de doenças respiratórias em crianças menores de três anos. Cerca de $50 \%$ dos resfriados são de origem viral, e culminam em prejuízos econômicos em relação aos cuidados médicos, e sociais pelas ausências escolares (LEOTTE et al., 2017).

A maior incidência de doenças respiratórias por causas virais em crianças menores de três anos se deve, principalmente, ao seu sistema imunológico e respiratório imaturo, que os torna mais propensos a infecções e coinfecções. Além disso, a idade interfere no ambiente e no comportamento individual. Em idades maiores, passam a maior parte do em outros locais, devido a atividades curriculares e extracurriculares, que envolvem locomoção e o contato com outros fatores de risco. Os entornos específicos e os padrões comportamentais individuais podem influenciar na exposição individual aos poluentes e nos padrões clínicos respiratórios (VIEIRA et al., 2012).

Fatores comportamentais e/ou domésticos (uso de cobertor de lã, tabagismo dos pais, contato com poeira doméstica, entre outros) parecem influenciar pouco sobre a saúde respiratória das crianças, em comparação aos demais mencionados. Embora haja efeito brando, crianças com alergia atópica, renite ou asma respondem mais severamente a poeira domiciliar (GUILHERME, 2012). Crianças fumantes passivas têm maiores riscos de apresentar sintomas respiratórios, bem como maior morbidade (SIGAUD, 2016), do mesmo modo que o tabagismo durante a gestação (SILVA et al., 2013b). O histórico familiar de asma também é fator de risco (SILVA et al., 2013b, GONÇALVES, 2016, BRANDÃO et al., 2017), e leva a estadia de 2,4 dias a mais no hospital em relação àquelas sem histórico familiar (SILVA et al., 2013b).

Nesse estudo elencamos vários fatores de risco para doenças respiratórias em crianças, principalmente a exposição a poluentes atmosféricos, seguida de condições climáticas naturais, causas virais, fatores comportamentais e/ou domésticos e história da doença na família. Infere-se que a exposição a associação de diferentes fatores pode agravar e aumentar a incidência das doenças respiratórias, e destaca-se que fatores como a poluição são originários de atividades antrópicas e, portanto, podem ser remediadas. Também salienta- 
se a necessidade de ampliar os estudos acerca dos efeitos da exposição a poluentes em crianças com menos de dois anos, devido a maior suscetibilidade dessa faixa etária.

Ainda, verificou-se que o poluente mais investigado nos estudos e que está relacionado a maior chance de desenvolvimento de doenças respiratórias em crianças é o MP2,5, e que este pode causar danos mesmo dentro dos limites considerados ideais. Portanto, a relação entre poluição atmosférica e internações hospitalares pode ser extrapolada pra cidades pequenas, onde a qualidade do ar ainda está de acordo com os parâmetros preconizados pela OMS.

A compreensão dos principais fatores de risco que estão associados as doenças respiratórias em crianças, é fundamental para planejar ações de saúde pública, com vistas a reduzir e prevenir a incidência dessas doenças em crianças.

\section{REFERÊNCIAS}

ALBUQUERQUE, M. C. et al. Acute respiratory viral infections in children in Rio de Janeiro and Teresopolis, Brazil. Revista Institucional de Medicina Tropical de São Paulo, v. 54, n. 5, p. 249-55, 2012.

AMBIENTE, M. D. M. Poluentes atmosféricos. 2018. Disponível em: < http://www.mma.gov.br/cidades-sustentaveis/qualidade-do-ar/poluentesatmosf\%C3\%A9ricos\#Material_particulado > .

ANDRADE FILHO, V. S. et al. Aerosols from biomass burning and respiratory diseases in children, Manaus, Northern Brazil. Revista de Saúde Pública, v. 47, n. 2, p. 239-47, 2013.

ARRUDA, E. et al. The burden of single virus and viral coinfections on severe lower respiratory tract infections among preterm infants: a prospective birth cohort study in Brazil. Pediatric Infecto Disease Journal, v. 33, n. 10, p. 9971003, 2014.

BRANDÃO, H. V. et al. Acute viral bronchiolitis and risk of asthma in schoolchildren: analysis of a Brazilian newborn cohort. Jornal de Pediatria, v. 93, n. 3, p. 223-229, 2017

CARVALHO, E. K. M. A. D., R. T.; CARVALHO, J. R. M. Análise da influência entre as variáveis meteorológicas e doenças respiratórias na cidade de Campina Grande, PB. Revista Brasileira de Climatologia, v. 18, n. 12, p. 6379, 2016.

CAVALCANTI, Y. W. F., I. A. et al. Determinação do Nível de Evidência Científica de Artigos sobre Prótese Total Fixa Implanto-Suportada. Revista Brasileira de Ciências da Saúde, v. 14, n. 4, p. 45-50, 2011.

CÉSAR, A. C. G. Material particulado fino estimado por modelo matemático e internações por pneumonia e asma em crianças. Revista Paulista de Pediatria, v. 34, p. 18-23, 2016.

CÉSAR, A. C. G. C. J., J. A.; NASCIMENTO, L. F. C. Association between NOx exposure and deaths caused by respiratory diseases in a medium-sized 
Brazilian city. Brazilian Journal of Medical and Biological Research, v. 48, n. 12, p. 1130-1135, 2015.

CESAR, A. C. G. N., L. F. C.; CARVALHO, J. A. Association between exposure to particulate matter and hospital admissions for respiratory disease in children. Revista de Saúde Pública, v. 47, n. 6, p. 1209-1212, 2013.

EPA. http://www.epa.gov / Acesso em: 01 de novembro de 2013.

FREITAS, M. S. et al. Prevalence of asthma symptoms and associated factors in schoolchildren from Brazilian Amazon islands. Journal of Asthma, v. 49, n. 6, p. 600-5, 2012.

GALVÃO, T. F. E. A. Principais itens para relatar revisões sistemáticas e metaanálises: a recomendação PRISMA. Epidemiologia e Serviços de Saúde, v. 24, n. 2, p. 335-342, 2015.

GHIO, A. J. et al. Biologic Effects of Oil Fly Ash. Environmental Health Perspectives, v. 110, 2002.

GONÇALVES, E. D. S. Associação entre variáveis clínicas relacionadas à asma em escolares nascidos com muito baixo peso com e sem displasia broncopulmonar. Revista Paulista de Pediatria, v. 24, n. 3, p. 271-280, 2016.

GURGUEIRA, S. A. et al. Rapid Increases in the Steady-State Concentration of Reactive Oxygen Species in the Lungs and Heart after Particulate Air Pollution Inhalation. Environmental Health Perspectives, v. 110, n. 8, 2002.

GUILHERME, E. V. E. A. Resposta cutânea a alérgenos ambientais em indivíduos atendidos em serviço de pneumologia, maringá, estado do paraná, Brasil. Acta Scientiarum - Health Sciences, v. 24, n. 1, p. 79-83, 2012.

LEOTTE, J. et al. Impact and seasonality of human rhinovirus infection in hospitalized patients for two consecutive years. Jornal de Pediatria, v. 93, n. 3, p. 294-300, 2017.

MOURA, M. et al. [Air quality and acute respiratory disorders in children]. Revista de Saúde Pública, v. 42, n. 3, p. 503-11, 2008.

NARDOCCI, A. C. D. F., C. U. et al. Poluição do ar e doenças respiratórias e cardiovasculares: estudo de séries temporais em Cubatão, São Paulo, Brasil. Cadernos de Saúde Pública, v. 29, n. 9, p. 1867-1876, 2013.

NASCIMENTO, A. P. S. et al. Associação entre concentração de partículas finas na atmosfera e doenças respiratórias agudas em crianças. Revista de Saúde Pública, v. 51, n. 3, p. 1-10, 2017.

ORONA, N. S. et al. Acute exposure to Buenos Aires air particles (UAP-BA) induces local and systemic inflammatory response in middle-aged mice: A time course study. Environmental Pollution, v. 208, p. 261-270, 2016.

PEDRAZA, D. F. Q., D.; SALES, M. C. Doenças infecciosas em crianças préescolares brasileiras assistidas em creches. Ciência e Saúde Coletiva, v. 19, n. 2, p. 511-528, 2014. 
RAJAGOPALAN, S.; BROOK, R. D. Air Pollution and Type 2 Diabetes Mechanistic Insights. Diabetes, v. 61, 3037-45, 2012.

RODRIGUES, P. C. O. I., E.; HACON, S. S. Distribuição espaço-temporal das queimadas e internações por doenças respiratórias em menores de cinco anos de idade em Rondônia, 2001 a 2010. Epidemiologia e Serviços de Saúde, v. 22 , n. 3, p. 455-464, 2013.

ROMAN, V. V. L. C. J., J. A. et al. Efeitos de poluentes do ar e doenças respiratórias utilizando dados estimados por modelo matemático. Revista Ambiente e Água, v. 10, n. 4, p. 825-831, 2015.

SANTANA, E. C., K. B. et al. Padrões de qualidade do ar: Experiência comparada Brasil, EUA e União Europeia. São Paulo: Instituto de Energia e Meio Ambiente, 2012.

SHEN, Y. et al. Non-linear increase of respiratory diseases and their costs under severe air pollution. Environmental Pollution, v. 224, p. 631-637, 2017.

SIGAUD, C. H. S. C. et al. Associação entre tabagismo passivo domiciliar e morbidade respiratória em pré-escolares. Revista da Escola de Enfermagem da USP, v. 50, n. 4, p. 562-568, 2016.

SILVA, A. M. et al. Particulate matter originating from biomass burning and respiratory. Revista de Saúde Pública, v. 47, n. 2, p. 345-52, 2013.

SILVA, E. R. et al. Severe lower respiratory tract infection in infants and toddlers from a non-affluent population: viral etiology and co-detection as risk factors. BMC Infecto Disease, v. 13, p. 41, 2013.

SOUZA, A. F., W. A. et al. Potenciais impactos da variabilidade climática sobre a morbidade respiratória em crianças, lactentes e adultos. Jornal Brasileiro de Pneumologia, v. 38, n. 6, p. 708-715, 2012.

SOUZA, J. B. R., V. A. et al. Componentes principais e modelagem linear generalizada na associação entre atendimento hospitalar e poluição do ar. Revista de Saúde Pública, v. 48, n. 3, p. 451-458, 2014.

VIEIRA, S. E. S., R. T. et al. Los contaminantes atmosféricos urbanos son factores de riesgo significativos para el asma y la neumonía en niños: influencia del lugar de medición de los contaminantes. Archivos de Bronchoneumologia, v. 48, n. 11, p. 389-395, 2012.

$\mathrm{XU}, \mathrm{X}$. et al. Effect of early particulate air pollution exposure on obesity in mice. Role of p47phox. Arteriosclerosis, Thrombosis and Vascular Biology, v. 30, n. 12, p. 2518-27, 2010.

WHITTEMORE, R.; KNAFL, K. The integrative review: updated methodology. Journal of Advanced Nursing, v. 52, n. 5, p. 546-53, 2005.

WHO. Health risks of air pollution in Europe - HRAPIE project New emerging risks to health from air pollution - results from the survey of experts. 2013. 